\title{
Presença francesa no Brasil
}

O ANO 2009 foi oficialmente o Ano da França no Brasil. Dentre as centenas de atividades realizadas, uma das que mais bem sintetizaram as intensas relações entre Brasil e França foi o ciclo de conferências promovido pelo Núcleo de Pesquisas Brasil-França (Nupebraf) do Instituto de Estudos Avançados da Universidade de São Paulo (IEA-USP), realizado no Centro Universitário $\mathrm{Ma}$ ria Antonia, durante o qual especialistas brasileiros e franceses das áreas de História, Antropologia, Literatura, Artes plásticas, Música, Teatro, Fotografia e Arquitetura trataram das relações entre os dois países.

O período contemplado pelas conferências retomou cronologicamente a extensa e ininterrupta relação franco-brasileira, partindo de reflexões sobre a França Antártica (século XVI) e chegando aos dias de hoje. O livro Cinco séculos de presença francesa no Brasil: invasões, missões, irrupções, organizado pela professora emérita da Faculdade de Filosofia Letras e Ciências Humanas da Universidade de São Paulo Leyla Perrone-Moisés, e publicado agora pela Edusp, reúne esse importante conjunto de trabalhos.

"O Brasil de Montaigne", que abre o volume, foi escrito por Frank Lestrignant e trata da importância do contato de Montaigne com índios brasileiros e com escritos de viajantes para a elaboração de suas reflexões sobre as noções de civilização e de barbárie. O Brasil lido por Montaigne o leva, por exemplo, a considerar que "cada qual chama de barbárie o que não é de seu costume". O modo como Montaigne lida com a alteridade, lembra Lestrignant, faz que Montaigne invente, em "Dos Canibais", a "heterologia", isto é, "um discurso do outro, que é ao mesmo tempo discurso sobre o outro e discurso em que fala o outro". E prossegue o autor: "a heterologia provê um espaço intermediário, um palco reversível, em que a última palavra não pertence necessariamente ao sujeito primeiro do discurso", podendo o enunciador ser também sujeito a crítica. A "declamação em eco" presente na retórica de Montaigne é também, e sobretudo, aquela do próprio ritual sacrificial a que se refere. Ao propor tal passagem, Lestrignant produz um espelhamento verbal altamente sugestivo, o que faz deste um dos mais instigantes textos do livro.

De grande interesse também é o segundo artigo, "Franceses no Maranhão: história de intérpretes", de Beatriz Perrone-Moisés. Nele, a autora retoma a trajetória de Charles des Vaux, jovem nobre responsável pela ideia da fundação da França Equinocial no século XVII, assim como a história de David Migan, jovem intérprete francês que viveu entre os índios tupi. O centro do argumento de Beatriz Perrone-Moisés é que "Des Vaux e Migan desempenham papéis tão ou mais vitais para a França equinocial quanto alguém como La Ravardière, personagem que a historiografia optou por reter". Ao colocar o que chama de "intérpretes-embaixadores" como protagonistas da história da França Equinocial, a antropóloga lança luz sobre estratégias fundamentais de contato e de conquista ainda pouco visíveis para a historiografia oficial. 
O terceiro e o quarto ensaios não tratam mais da época das invasões e sim das ditas "missões" do século XIX. O que está em jogo, primeiramente, é o questionamento da própria noção de missão, pois, como aponta Leyla Perrone-Moisés em sua apresentação, “as últimas pesquisas sobre o assunto mostram que os artistas franceses acolhidos pela corte de dom João VI, para fundar a primeira Escola de Belas Artes do Brasil, foram missionários voluntários".

Em "A Arcádia francesa chega ao Brasil: as telas melancólicas de Nicolas-Antoine Taunay", Lilia Moritz Schwarcz reflete sobre o modo como a complexa relação entre os artistas franceses e a recém-chegada corte portuguesa foi sendo acordada. Destaca a pesquisadora que os artistas franceses logo perceberam que sua verdadeira função seria "construir cenários rápidos e dar grandiosidade a essa corte imigrada". Nesse contexto, coube a Nicolas-Antoine Taunay a difícil tarefa de tentar "traduzir" para os trópicos a experiência de uma pintura de representação do Estado de cunho neoclássico. É o choque de culturas expresso na pintura, por exemplo, pela dificuldade em retratar a escravidão, que faz da experiência de Taunay um retrato dos "mal entendidos" que envolvem a vinda dos artistas franceses ao Brasil.

O ensaio "Jean-Baptiste Debret: um filho da Revolução Francesa diante do Brasil nascente", do filósofo Jacques Leenhardt, aponta para esse outro importante artista do período, o pintor Jean-Baptiste Debret. Assim como Taunay, ele depara com o descompasso entre a realidade brasileira e a ética neoclássica, “inaplicável às circunstâncias brasileiras". Debret, entretanto, abandona a pompa monárquica e debruça-se sobre a vida da rua, o que faz dele, nas palavras de Leenhardt, uma das mais importantes "testemunhas das transformações mais dramáticas que afetam o país".

O texto seguinte, "O teatro francês no Brasil do século XIX”, de João Roberto de Faria, trata da presença francesa nos meios teatrais, presença que se dá tanto pelo predomínio do repertório dramático em nossos palcos como pela vinda de companhias dramáticas e de grandes artistas franceses, sobretudo ao Rio de Janeiro. Roberto de Faria destaca a figura de João Caetano, responsável, a partir dos anos 1830, pela adoção do repertório dramático francês de modo hegemônico, tendência que, entre compreensões e incompreensões, atravessa todos os movimentos literários do período, desde o romantismo até o naturalismo, estando na base da formação de nosso repertório nacional também. A presença de artistas franceses em palcos brasileiros foi também avassaladora, sendo responsável por parte considerável do que se convencionou chamar de dramaturgia séria. Essa forte presença não parece ter levado, contudo, à produção de um teatro brasileiro inovador, o que leva o pesquisador a afirmar que, tanto na formação de repertório quanto de companhias, "surpreende e incomoda que não tenhamos tido no período uma dramaturgia mais rica, sintonizada pelo menos com aquela predominante nos palcos franceses".

$\mathrm{O}$ segundo texto dedicado à literatura do século XIX é "A França literária de Machado de Assis", de Gilberto Pinheiro Passos. Partindo do conceito de paródia, seja temática, seja estilística, Pinheiro Passos desenvolve acurada leitura do modo como Machado de Assis retoma o gênero das "Memórias", pre- 
sente tanto na obra Memorial de Santa- Helena de Las Casas, como nas Mémoires d'outre tombe de Chateaubriand, renovando-o. Essa "criação de memórias póstumas à brasileira" surge para o pesquisador como uma brilhante "confissão da incapacidade ou desinteresse dessa parcela social [a classe dominante] de entender e modificar o país". Pinheiro Passos estabelece também importante paralelo entre as Illusions perdues de Balzac e Quincas Borba, além de apontar de modo preciso para as leituras de Pascal na elaboração da complexa Capitu. O vasto conhecimento da obra de Machado de Assis ainda leva o pesquisador a se debruçar sobre a presença de Racine em Esaú e Jacó. O raro poder de síntese de Pinheiro Passos permite, em pouco mais de uma dezena de páginas, retomar grandes linhas de força do romance machadiano.

A presença francesa no século XX, por sua vez, é analisada em três ensaios. Em "Darius Milhad e o Brasil: o olhar do viajante, através de seus textos (1917-1949)", Manoel Corrêa do Lago se debruça sobre a estada do compositor francês no Brasil entre 1917 e 1918. De forma bastante detalhada, retoma tanto as conferências de Milhaud que tem o Brasil como tema e as composições que realizou inspirado em seus estudos de ritmos brasileiros, assim como suas atividades concertísticas e sua circulação no meio carioca. Em sua conclusão, Lago destaca que os escritos de Milhaud em sua fase brasileira "constituem, no seu conjunto, um tesouro de informações, de caráter etnomusicológico, sociológico e musical, sobre o Brasil que emergia da Primeira Guerra Mundial".

O entre-guerras é também o período tratado em "Fascínio e rejeição: Blaise
Cendrars e Benjamin Péret no Brasil", de Carlos Augusto Calil. Grande conhecedor da obra de Cendrars e de Péret, Calil apresenta as contradições e descobertas que envolvem a presença desses artistas franceses no Brasil. Se, por um lado, a presença de Cendrars foi “decisiva para a consolidação do movimento modernista no Brasil", por outro, o poeta não resiste à "idealização do Brasil”. Em relação a Péret, o poeta surrealista acaba expulso do Brasil em 1930 e, quando volta ao país na década de 1950, acaba preso, levando Calil a falar em dupla rejeição do Brasil em relação ao "inconveniente poeta". Assim, em ambos os casos, "a irredutível experiência brasileira, cujo elemento irracional enseja um movimento de suspeita e fascínio, ganha identidade pelo mútuo estranhamento".

O fascínio exercido pelo Brasil também é analisado em "Pierre Verger e Marcel Gautherot, da França ao Brasil: experiências cruzadas e convenções de representação", de Heliana Angotti-Salgueiro. Como destaca o ensaio, se é possível identificar nas imagens dos fotógrafos franceses "convenções de representação do exotismo", os clichês de seus retratos etnográficos "não maquiavam ou estetizavam a pobreza, nem dignificavam ideologicamente seus modelos" e, sim, representavam um modo de olhar que, segundo Angotti-Salgueiro, pode ser compreendido como um "humanismo documentário".

Diferentemente dos textos anteriores, os quatro ensaios que encerram o volume apontam para possíveis futuros cruzamentos. Imagem do próprio Ano da França no Brasil, os textos "A literatura Francesa de hoje", de Gilles Lapouge; "A irrupção da arte contemporânea nos museus de arte antiga", de Jean Ga- 


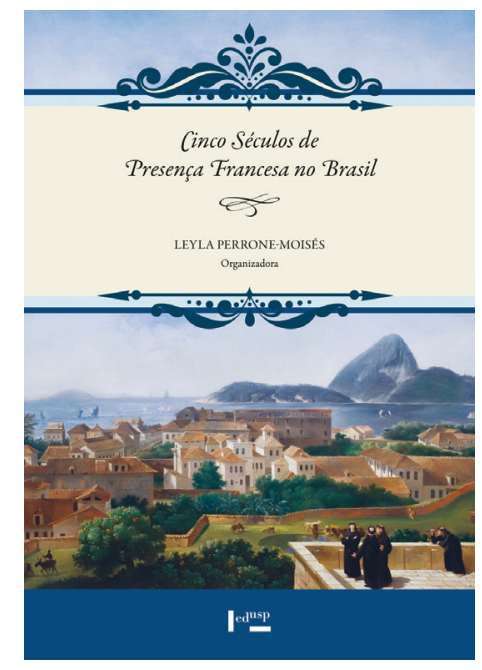

PERRONE-MOYSÉS, L. Cinco séculos de presença francesa no Brasil: invasões, missões, irrupções. São Paulo: Edusp, 2013.

lard; "A arquitetura expressiva ou o pós-modernismo à francesa", de Françoise Gaillard; e "A crise da literatura francesa e da irradiação intelectual da França no mundo", de Pierre Rivas, permitem ao leitor entrar em contato com questões que alimentam hoje o debate de ideias na França, abrindo espaço para que, neste século que se inicia, o contato entre a cultura brasileira e a cultura francesa prossiga profícuo em seus choques, encontros e equívocos, como apontam os instigantes ensaios que compõem o livro Cinco séculos de presença francesa no Brasil: invasões, missões, irrupções.

Álvaro Faleiros é doutor em Letras pela Universidade de São Paulo (2003); professor de Literatura Francesa da FFLCHUSP. @- faleiros@usp.br

I Faculdade de Filosofia, Letras e Ciências Humanas, Universidade de São Paulo, São Paulo/SP, Brazil. 